\title{
Modes and nodes explain the mechanism of action of vortioxetine, a multimodal agent (MMA): blocking 5HT3 receptors enhances release of serotonin, norepinephrine, and acetylcholine
}

\author{
Stephen M. Stahl \\ ISSUE: \\ Vortioxetine is an antidepressant with multiple pharmacologic modes of action at \\ targets where serotonin neurons connect with other neurons. 5HT3 receptor \\ antagonism is one of these actions, and this leads to increased release of \\ norepinephrine (NE), acetylcholine (ACh), and serotonin (5HT) within various \\ brain circuits.
}

\section{Take-Home Points \\ - Vortioxetine is an antagonist at serotonin (5HT) 5 HT3 receptors. \\ - Vortioxetine also targets the serotonin transporter (SERT), 5HT1A, 5HT1B, 5HT1D, and 5HT7 receptors. \\ - 5HT3 antagonism enhances not only the release of $5 \mathrm{HT}$, but also of norepinephrine (NE) and acetylcholine (ACh), which may be linked to its antidepressant and procogni- tive properties}

Vortioxetine is a "multimodal" agent that simultaneously acts at 6 pharmacologic targets with 3 modes of action (Figure 1) ${ }^{1-4}$ :

1. Inhibition of the serotonin $(5 \mathrm{HT})$ transporter or SERT

2. Actions at several G-protein linked receptors (agonist actions at 5HT1A receptors, partial agonist actions at 5HT1B receptors, antagonist actions at 5HT1D and 5HT7 receptors)

3. Inhibition of a ligand-gated ion channel (the 5HT3 receptor)
We have previously described the mechanisms whereby vortioxetine's actions at 5HT receptors work together to enhance the release of $5 \mathrm{HT}^{5}$ and glutamate ${ }^{6}$ and to inhibit the release of GABA (gamma amino butyric acid). ${ }^{6}$ Here we discuss how antagonism of 5HT3 receptors by vortioxetine (Figure 1) is one of the hypothetical mechanisms that also leads to enhanced release of $5 \mathrm{HT}$ as well as to enhanced release of $\mathrm{NE}$ and $\mathrm{ACh} \cdot{ }^{3,4,7,8}$ An explanation of vortioxetine's hypothetical actions at additional $5 \mathrm{HT}$ receptors that also contribute to the enhanced release of ease of $\mathrm{NE}$ and $\mathrm{ACh}$, as well as to the release of DA and histamine HA, has been discussed elsewhere. $^{3,4,7,8}$

\section{Serotonin and Glutamate Regulate Each Other}

It is well known that $5 \mathrm{HT}$ regulates its own release via feedback mediated by autoreceptors that are located on the 5HT neurons themselves. ${ }^{5,9,10}$ However, 5HT can also regulate its own release via postsynaptic 5HT3 receptors located within a 3-neuron feedback loop (Figure 2A). ${ }^{10-15}$ The first neuron in this feedback loop is serotonergic, and provides input to prefrontal 


\section{BRAINSTORMS -Clinical Neuroscience Update Part 3}

Figure 1. Icon of vortioxetine showings its 6 pharmaco-

logic mechanisms. Highlighted here is 5HT3 antagonism, linked to enhanced release of serotonin (5HT), NE, and $\mathrm{ACh}$.

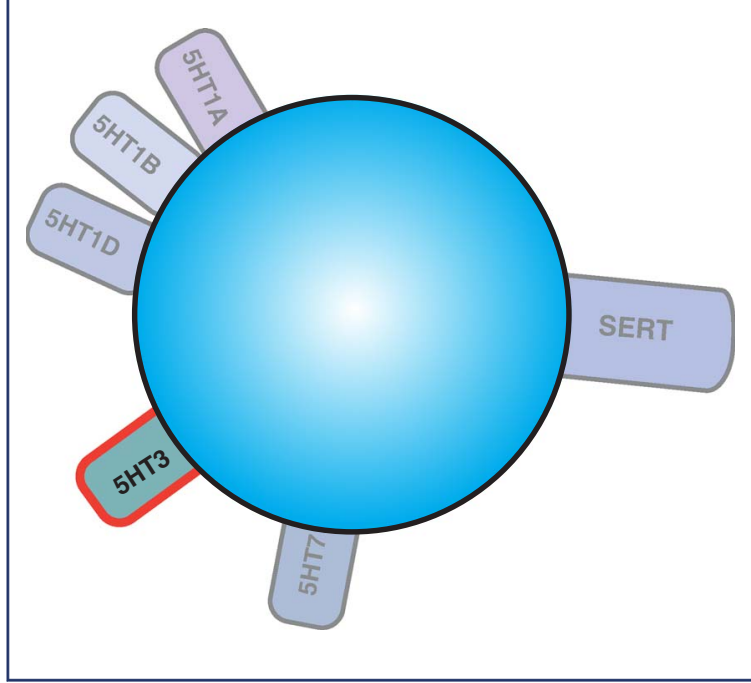

cortex and hippocampus. There, 5HT stimulates excitatory $5 \mathrm{HT} 3$ receptors on a GABAergic interneuron (Figure 2A). This second neuron in the feedback loop is a type of GABAergic interneuron that does not stain positively for the calcium binding protein parvalbumin and is regular spiking, late spiking, or bursting in its firing pattern. ${ }^{6,10-28}$ The GABA that is released from this second neuron in turn inhibits the third neuron in the feedback loop, namely, a pyramidal neuron in the prefrontal cortex or hippocampus (Figure 2A). This pyramidal neuron finally projects back to the midbrain raphe where it can release glutamate and stimulate 5HT release (Figure 2A). Thus, 5HT regulates downstream glutamate release, which in turn regulates $5 \mathrm{HT}$ release (Figure 2A).

Although SSRIs increase 5HT levels by SERT inhibition, activation of $5 \mathrm{HT} 3$ receptors by $5 \mathrm{HT}$ in this feedback loop leads to inhibition of cortical pyramidal neurons due to activation of GABAergic inhibition, and thus no amplification of 5HT release by downstream glutamate (Figure 2B). ${ }^{10-15}$ Contrast this with vortioxetine, which not only enhances $5 \mathrm{HT}$ via SERT inhibition, but also blocks 5HT3 receptors (Figure 2C). 5HT3 receptor antagonism removes GABAergic inhibition and thus disinhibits pyramidal neurons, further enhancing 5HT release by glutamatergic stimulation of serotonergic neurons in the midbrain raphe (Figure 2C). 3,4,16,17
Figure 2A. Serotonin and glutamate regulate each other: role of 5HT3 receptors. Shown here is a 3-neuron feedback circuit, beginning with the $5 \mathrm{HT}$ neuron, terminating upon a 5HT3 receptor localized upon a second neuron: a GABAergic interneuron that does not stain positively for the calcium binding protein parvalbumin and has a firing pattern that is regular spiking, late spiking or bursting. GABA released from this second neuron in turn inhibits the third neuron in this feedback circuit: cortical pyramidal neurons that release glutamate at nerve terminals that project back to the midbrain raphe and that stimulate 5HT release.

Serotonin and Glutamate Regulate Each Other

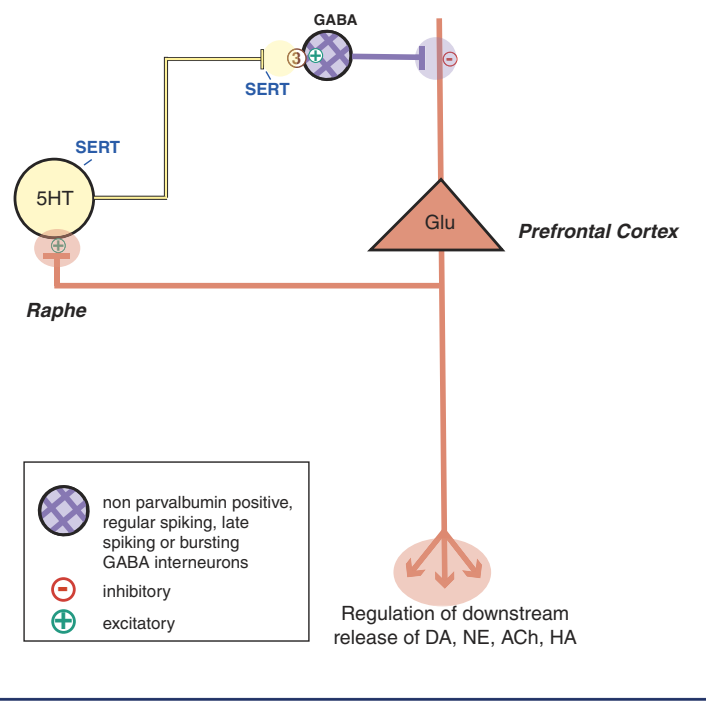

\section{Serotonergic Regulation of Norepinephrine (NE) and} Acetylcholine (ACh) Release

$5 \mathrm{HT}$ regulates the downstream release of many neurotransmitters, not only $5 \mathrm{HT}$ itself, but also NE, ACh, DA, and HA. 3,4,9,10,18,24 Stimulation of postsynaptic 5HT1A receptors increases cortical and hippocampal release of $\mathrm{ACh}^{29,30}$ and NE. ${ }^{31,32}$ Although the microanatomy is still being worked out, blockade of postsynaptic serotonergic heteroreceptors on presynaptic nerve terminals could theoretically be another mechanism whereby $\mathrm{ACh}, \mathrm{NE}, \mathrm{DA}$, and HA release is enhanced. ${ }^{8,10}$ These various mechanisms are discussed elsewhere. ${ }^{3,4,7-10}$ Here we discuss and illustrate how 5HT3 receptors regulate both $\mathrm{NE}$ and $\mathrm{ACh}$ release. Specifically, 5HT stimulation of 5HT3 receptors causes inhibitory output from GABAergic interneurons, and this inhibits the release of NE and ACh from presynaptic nerve terminals (Figure 3A). ${ }^{19,20}$ Thus, when SSRIs elevate 5HT levels, this causes GABA to be released, 


\section{BRAINSTORMS -Clinical Neuroscience Update Part 3}

Figure 2B. When 5HT levels increase after administration of an SSRI, the activation of $5 \mathrm{HT} 3$ receptors by $5 \mathrm{HT}$ leads to stimulation of GABA release; this in turn inhibits cortical pyramidal neurons, and thus there is no amplification of 5HT release by downstream glutamate.

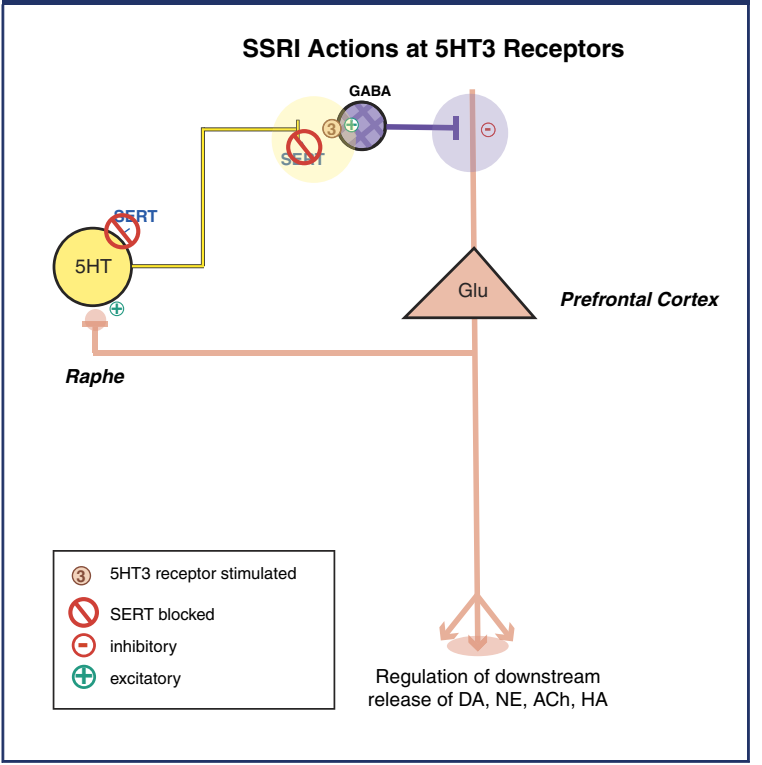

which in turn inhibits both $\mathrm{NE}$ and $\mathrm{ACh}$ release (Figure 3B). ${ }^{19,20}$ By contrast, vortioxetine blocks the $5 \mathrm{HT} 3$ receptor so that GABA is not released by $5 \mathrm{HT}$, and therefore both $\mathrm{NE}$ and $\mathrm{ACh}$ are disinhibited-ie, their levels are enhanced (Figure 3C). ${ }^{2,8}$

\section{Potential Clinical Significance of 5HT3 Antagonism}

Enhanced release of 5HT by combining 5HT3 antagonism with SERT inhibition likely contributes to the antidepressant actions of vortioxetine. ${ }^{1-4,8,24}$ Enhanced $5 \mathrm{HT}$ release by combining SERT inhibition with several of vortioxetine's other actions at 5HT receptorsnamely 5HT1A agonism, 5HT1B partial agonism, 5HT1D antagonism, and 5HT7 antagonism-was discussed in a previous Brainstorms article. ${ }^{5}$ Enhanced release of $\mathrm{NE}$ and $\mathrm{ACh}$ levels is also likely an important feature of vortioxetine's clinical activity. That is, NE and ACh levels are increased with selective 5HT3 antagonists that also exhibit procognitive activity in animal models. ${ }^{33-37}$ Thus, vortioxetine's procognitive actions in both animal models ${ }^{24,38-41}$ and in patients with major depressive disorder ${ }^{42-44}$ may be mediated in part by its 5HT3 antagonist properties and the enhanced release of both NE and ACh that accompany 5HT3 receptor antagonism. Adding 5HT3 antagonism
Figure 2C. In contrast to the actions of SSRIs shown in

Figure $2 \mathrm{~B}$, shown here are the actions of vortioxetine,

which not only enhance 5HT via SERT inhibition, but also block 5HT3 receptors. The blockade of 5HT3 receptors

removes GABA inhibition and thus disinhibits pyramidal neurons. This in turn enhances downstream release of

5HT due to glutamatergic stimulation of serotonergic neurons in the midbrain raphe.

Vortioxetine Actions at 5HT3 Receptors: Enhance 5HT Release by Disinhibiting Glutamate Release

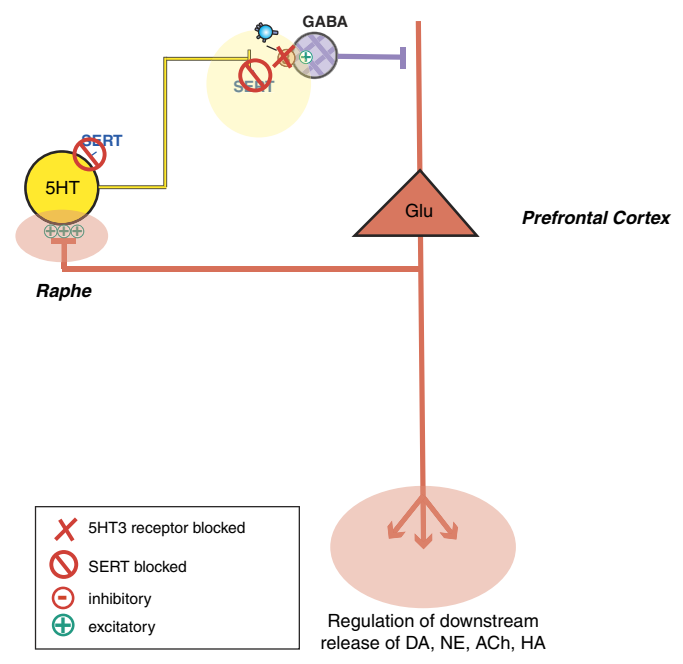

Figure 3A. Serotonin (5HT) 3 receptor mediated regulation of ACh and NE release. 5HT stimulation of 5HT3 receptors causes inhibitory output from GABAergic interneurons, and this inhibits the release of $\mathrm{NE}$ and $\mathrm{ACh}$ from presynaptic nerve terminals.

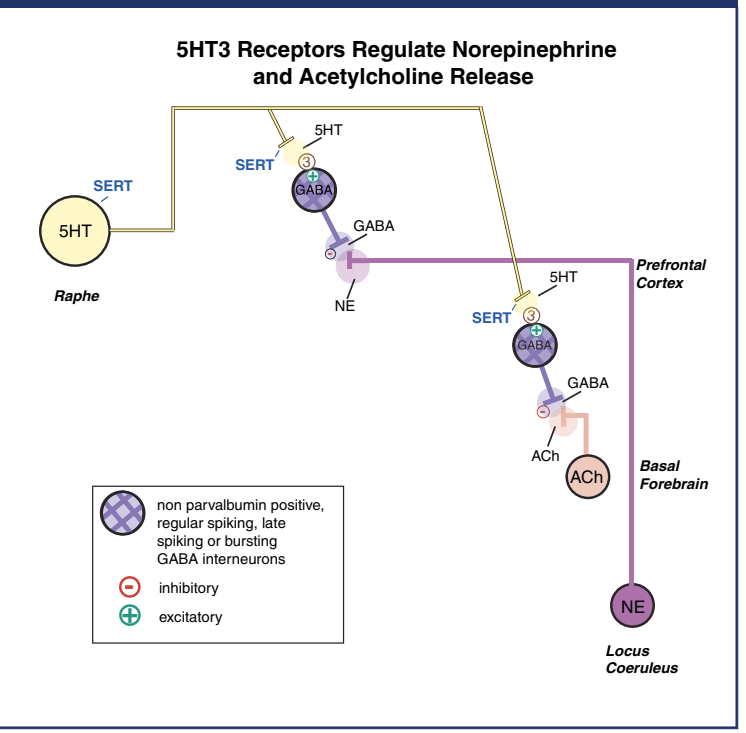




\section{BRAINSTORMS -Clinical Neuroscience Update Part 3}

Figure 3B. SSRIs inhibit the release of $\mathrm{ACh}$ and NE via

5HT3 receptors. When SSRIs increase 5 HT levels by SERT inhibition, GABA is released, which in turn inhibits both $\mathrm{NE}$ and $\mathrm{ACh}$ release.

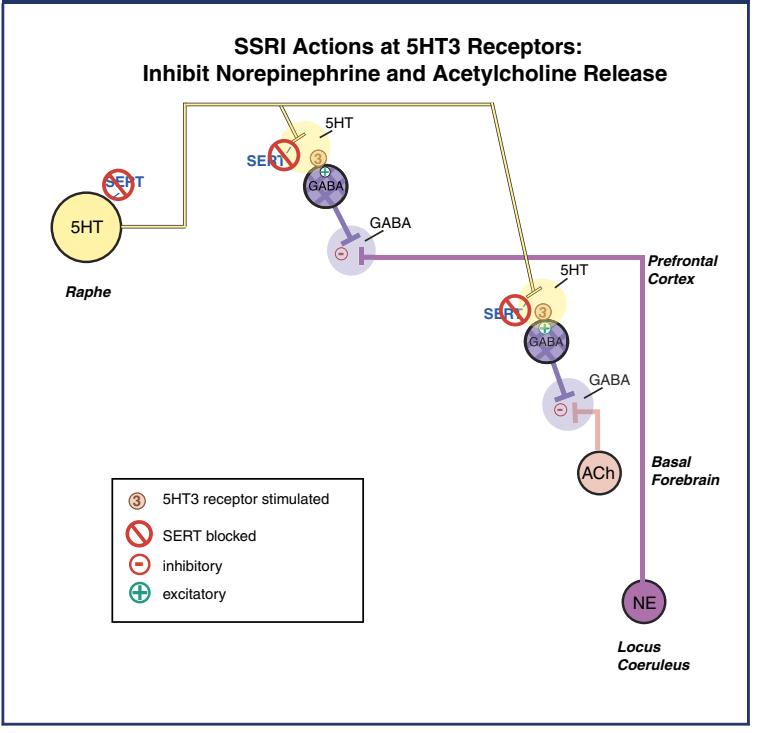

Figure 3C. Vortioxetine enhances the release of $\mathrm{ACh}$ and NE by blocking $5 \mathrm{HT} 3$ receptors. By contrast with SSRI actions shown in Figure 3B, vortioxetine blocks the 5HT3 receptor so that GABA is not released by $5 \mathrm{HT}$, and therefore both $\mathrm{NE}$ and $\mathrm{ACh}$ are disinhibited-ie, their levels are enhanced.

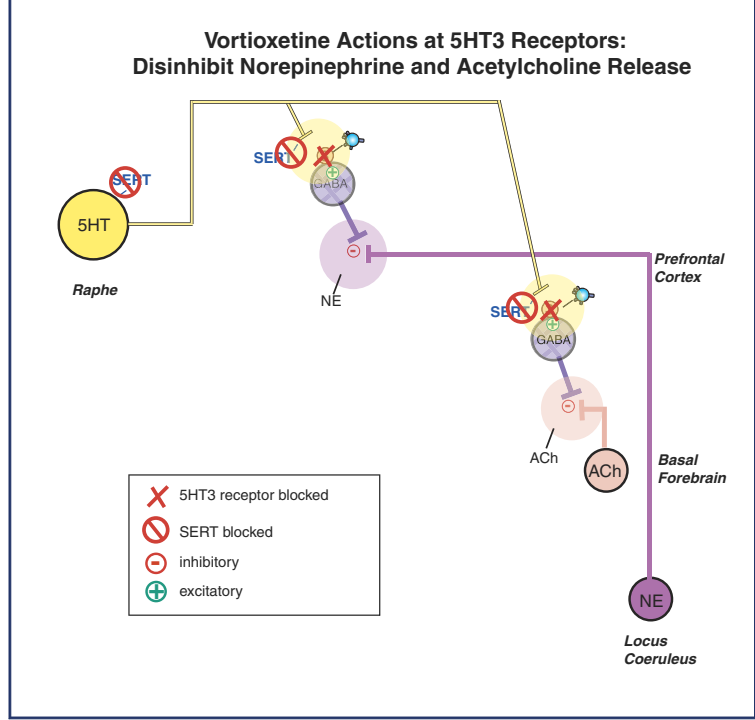

to SSRI actions could potentially enhance not only the antidepressant actions of SSRI activity but also add procognitive actions to antidepressant actions via increased release of $5 \mathrm{HT}, \mathrm{ACh}$, and NE. This possibility fits with the notion that neurotransmitters may theoretically "tune" the malfunctioning brain circuits that cause psychiatric symptoms. ${ }^{6,16,45,46}$ The release of $5 \mathrm{HT}, \mathrm{NE}$, and ACh by vortioxetine could theoretically improve the efficiency of information processing in maladaptive brain circuits by facilitating longterm potentiation, synaptic plasticity, and enhanced pyramidal neuron activity leading to improvement not only of mood but also of cognitive symptoms in major depressive disorder.

\section{References:}

1. Mørk A, Pehrson A, Brennum LT, et al. Pharmacological effects of Lu AA21004: a novel multimodal compound for the treatment of major depressive disorder. J Pharmacol Exp Ther. 2012; 340(3): 666-675.

2. Bang-Andersen $\mathrm{B}$, Ruhland $\mathrm{T}$, Jorgensen $\mathrm{M}$, et al. Discovery of 1-[2-(2,4-dimethylphenylsulfanyl)phenyl]piperazine

(Lu AA21004): a novel multimodal compound for the treatment of major depressive disorder. J Med Chem. 2011; 54(9): 3206-3221.

3. Pehrson AL, Cremers T, Bétry C, et al. Lu AA21004, a novel multimodal antidepressant, produces regionally selective increases of multiple neurotransmitters - a rat microdialysis and electrophysiology study. Eur Neuropsychopharmacol. 2013; 23(2): 133-145.

4. Sanchez C, Asin KE, Artigas F. Vortioxetine, a novel antidepressant with multimodal activity: review of preclinical and clinical data. Pharmacol Ther. 2015; 145: 43-57.

5. Stahl SM. Modes and nodes explain the mechanism of action of vortioxetine, a multimodal agent (MMA): enhancing serotonin release by combining serotonin $(5 \mathrm{HT})$ transporter inhibition with action at 5HT receptors (5HT1A, 5HT1B, 5HT1D, 5HT7 receptors). CNS Spectr. 2015; 20(2): 93-97.

6. Stahl SM. Modes and nodes explain the mechanism of action of vortioxetine, a multimodal agent (MMA): modifying serotonin's downstream effects on glutamate and GABA (gamma-aminobutyric acid) release by blocking $5 \mathrm{HT} 3$ and $5 \mathrm{HT} 7$ receptors. CNS Spectr In press.

7. Stahl SM. Modes and nodes explain the mechanism of action of vortioxetine, a multimodal agent (MMA): actions at serotonin receptors may enhance downstream release of four pro-cognitive neurotransmitters. CNS Spectr In press.

8. Mørk A, Montezinho LP, Miller S. Vortioxetine (Lu AA21004), a novel multimodal antidepressant, enhances memory in rats. Pharmacol Biochem Behav. 2013; 105: 41-50.

9. Stahl SM. Stahl's Essential Psychopharmacology. 4th ed. Cambridge, UK: Cambridge University Press; 2013.

10. Fink KB, Gothert M. 5HT receptor regulation of neurotransmitter release. Pharmacol Rev. 2007; 59(4): 360-417.

11. Gehlert DR, Gackenheimer SL, Wong DT, Robertson DW. Localization of 5-HT3 receptors in the rat brain using [3H] LY278584. Brain Res. 1991; 553(1): 149-154.

12. Puig MV, Santana N, Celada P, Mengod G, Artigas F. In vivo excitation of GABA interneurons in the medial prefrontal cortex through 5-HT3 receptors. Cereb Cortex. 2004; 14(12): 1365-1375.

13. Morales M, Battenberg E, Bloom FE. Distribution of neurons expressing immunoreactivity for the $5 \mathrm{HT} 3$ receptor subtype in the rat brain and spinal cord. J Comp Neurol. 1998; 402(3): 385-401. 


\section{BRAINSTORMS—Clinical Neuroscience Update Part 3}

14. Morales M, Bloom FE. The 5-HT3 receptor is present in different subpopulations of GABAergic neurons in the rat telencephalon. J Neurosci. 1997; 17(9): 3157-3167.

15. Ashby CR Jr, Minabe Y, Edwards E, Wang RY. 5-HT3-like receptors in the rat medial prefrontal cortex: an electrophysiological study. Brain Res. 1991; 550(2): 181-191.

16. Dale E, Zhang H, Leiser S, et al. Vortioxetine disinhibits pyramidal cell function and enhances synaptic plasticity in rat hippocampus. J Psychopharmacol. 2014; 28(10): 891-902.

17. Bétry C, Pehrson AL, Etievant A, et al. The rapid recovery of $5 \mathrm{HT}$ cell firing induced by the antidepressant vortioxetine involves 5HT3 receptor antagonism. Int J Neuropsychopharmacol. 2013; 16(5): 1115-1127.

18. Artigas F. Serotonin receptors involved in antidepressant effects. Pharmacol Ther. 2013; 137(1): 119-131.

19. Matsumoto M, Yoshioka M, Togashi H, Tochihara M, Ikeda T, Saito $\mathrm{H}$. Modulation of norepinephrine release by serotonergic receptors in the rat hippocampus as measured by in vivo microdialysis. J Pharmacol Exp Ther. 1995; 272(3): 1044-1051.

20. Yan Z. Regulation of GABAergic inhibition by serotonin signaling in prefrontal cortex: molecular mechanisms and functional implications. Mol Neurobiol. 2002; 26(2-3): 203-216.

21. Siarey RJ, Andreasen M, Lambert JDC. Serotoninergic modulation of excitability in area CA1 of the in vitro rat hippocampus. Neurosci Lett. 1995; 199(3): 211-214.

22. Zhou F, Hablitz JJ. Activation of serotonin receptors modulates synaptic transmission in rat cerebral cortex. J Neurophysiol. 1999; 82(6): 2989-2999.

23. Giovannini MG, Ceccarelli I, Molinari B, Cecci M, Goldfarb J, Blandina P. Serotonergic modulation of acetylcholine release from cortex of freely moving rats. J Pharmacol Exp Ther. 1998; 285(3): 1219-1225.

24. Pehrson AL, Sanchez C. Serotonergic modulation of glutamate neurotransmission as a strategy for treating depression and cognitive dysfunction. CNS Spectr. 2014; 19(2): 121-133.

25. Puig MV, Gulledge AT. Serotonin and prefrontal cortex function: neurons, networks, and circuits. Mol Neurobiol. 2011; 44(3): 449-464.

26. Kubota Y. Untangling GABAergic wiring in the cortical microcircuit. Curr Opin Neurobiol. 2014; 26: 7-14.

27. Adesnik H, Scanziani M. Lateral competition for cortical space by layer-specific horizontal circuits. Nature. 2010; 464(7292): 1155-1160.

28. Gottlieb JP, Keller A. Intrinsic circuitry and physiological properties of pyramidal neurons in rat barrel cortex. Exp Brain Res. 1997; 115(1): 47-60.

29. Izumi J, Washizuka M, Miura N, Hiraga Y, Ikeda Y. Hippocampal serotonin 5HT1A receptor enhances acetylcholine release in conscious rats. J Neurochem. 1994; 62(5): 1804-1808.

30. Consolo S, Ramponi S, Ladinsky H, Baldi G. A critical role for D1 receptors in the 5HT1A-mediated facilitation of in vivo acetylcholine release in rat frontal cortex. Brain Res. 1996; 707: 320-323.

31. Suzuki M, Matsuda T, Asano S, Somboonthum P, Takuma K, Baba A. Increase of noradrenaline release in the hypothalamus of freely moving rat by postsynaptic 5-hydroxytryptamine 1A receptor activation. Br J Pharmacol. 1995; 115(4): 703-711.
32. Suwabe A, Kubota M, Niwa M, Kobayashi K, Kanba S. Effect of a 5HT1A receptor agonist, flesinoxan, on the extracellular noradrenaline level in the hippocampus and on the locomotor activity of rats. Brain Res. 2000; 858(2): 393-401.

33. Brambilla A, Ghiorzi A, Pitsikas N, Borsini F. DAU 6215, a novel 5 HT3 receptor antagonist selectively antagonizes scopolamineinduced deficit in a passive avoidance task, but not scopolamine induced hypermotility in rats. J Pharm Pharmacol. 1993; 45(9): 841-843.

34. Fontana DJ, Daniels SE, Henderson C, Eglen RM, Wong EH. Ondansetron improves cognitive performance in the Morris water maze spatial navigation task. Psychopharmacol (Berl). 1995; 120(4): 409-417.

35. Pitsikas N, Borsini F. Itasetron (DAU 6215) prevents age-related memory deficits in the rat in a multiple choice avoidance task. Eur J Pharmacol. 1996; 311(2-3): 115-119.

36. Roychoudhury M, Kulkarni SK. Effects of ondansetron on shortterm memory retrieval in mice. Methods Find Exp Clin Pharmacol. 1997; 19(1): 43-46.

37. Arnsten AF, Line CH, Van Dyck CH, Stanhope KJ. The effects of 5 HT3 receptor antagonists on cognitive performance in aged monkeys. Neurobiol Aging. 1997; 18(1): 21-28.

38. du Jardin KG, Jensen JB, Sanchez C, Pehrson AL. Vortioxetine dose dependently reverses $5 \mathrm{HT}$ depletion induced deficits in spatial working and object recognition memory: a potential role of 5HT1A receptor agonism and 5HT3 receptor antagonism. Eur Neuropsychopharmacol. 2014; 24(1): 160-171.

39. Jensen JB, du Jardin KG, Song D, et al. Vortioxetine, but not escitalopram or duloxetine, reverses memory impairment induced by central $5 \mathrm{HT}$ depletion in rats: evidence for direct $5 \mathrm{HT}$ receptor modulation. Eur Neuropyschopharmacol. 2014; 24(1): 148-159.

40. Li Y, Sanchez C, Gulinello M. Memory impairment in old mice is differentially sensitive to different classes of antidepressants. Eur Neuropsychopharmacol. 2013; 23(Suppl 2): S282.

41. Wallace A, Pehrson AL, Sánchez C, Morilak DA. Vortioxetine restores learning impaired by $5 \mathrm{HT}$ depletion or chronic intermittent cold stress in rats. Int J Neuropsychopharmacol. 2014; 17(10): 1695-1706.

42. Katona C, Hansen T, Olsen CK. A randomized, double blind, placebo controlled, duloxetine referenced, fixed dose study comparing the efficacy and safety of Lu AA21004 in elderly patients with major depressive disorder. Int Clin Psychopharmacol. 2012; 27(4): 215-223.

43. McIntyre RS, Lophaven S, Olsen C. A randomized, double-blind, placebo controlled study of vortioxetine on cognitive function in depressed adults. Int J Neuropsychopharmacol. 2014; 17(10): 1557-1567.

44. Mahableshwarkar AR, Zajecka J, Jacobson W, Chen Y, Keefe RSE. A randomized, placebo-controlled, active-reference, double blind, flexible dose study of the efficacy of vortioxetine on cognitive function in major depressive disorder. Neuropsychopharmacology In press. DOI: 10.1038/npp.2015.52.

45. Insel T, Cuthbert B, Garvey M, et al. Research domain criteria (RDoC): toward a new classification framework for research on mental disorders. Am J Psychiatry. 2010; 167(7): 748-751.

46. Stahl SM. The last diagnostic and statistical manual (DSM): replacing our symptom-based diagnoses with a brain circuit-based classification of mental illnesses. CNS Spectr. 2013; 18(2): 65-68. 